\title{
Genomic DNA
}

National Cancer Institute

\section{Source}

National Cancer Institute. Genomic DNA. NCI Thesaurus. Code C95940.

The DNA that is part of the normal chromosomal complement of an organism. 